\title{
INCREASED MOTIVATION FOR PHYSICAL ACTIVITY AMONG READERS OF LIFESTYLE INTERVENTION ARTICLES
}

\author{
Leif Inge Tjelta, Gerd Lise Nordbotten, Sindre M. Dyrstad \\ Department of Education and Sports Science, University of Stavanger, \\ Stavanger, Norway
}

\begin{abstract}
The main purpose of this study was to investigate if readers of lifestyle intervention articles published in a newspaper became more motivated for physical activity (PA). A secondary aim was to chart reader characteristics like sex, age and PA level. In 2014, a regional newspaper with 152000 readers in Stavanger, Norway followed the story of four untrained adults trying to become physically fit. Their goal was to run an $8.2 \mathrm{~km}$ park race after 13 weeks of training. A panel of 623 newspaper readers answered a questionnaire about their own PA level and motivation to increase their PA level after reading the articles. Twenty percent of the readers (127 of 623 ) reported that they always or usually read the intervention articles, which was equal to the number who never read these articles. There was no significant difference in the distribution of men and women within these different categories. Sixteen percent of the reader panel (estimated to 24000 readers) reported that they were motivated to become more physically active after reading the articles. The study indicates a great potential for promoting a healthy lifestyle by publishing lifestyle interventions in a newspaper.
\end{abstract}

Keywords: Newspaper coverage; health; lifestyle; running

\section{INTRODUCTION}

In Norway, $31 \%$ of the adult population meets the recommended requirement for $150 \mathrm{~min} /$ week of moderate to vigorous physical activity (MVPA) [9], and only $10 \%$ of U.S. adults meet the same physical activity (PA) 
guidelines [15]. Several studies have shown that public health efforts can successfully increase PA among inactive adults $[10,11]$. An increasing focus in health, fitness and exercise features in TV, newspapers and magazines has been shown to have the capacity to bring attention to health issues $[4,6,8]$. However, Caburnay et al. [2] who measured the coverage and content of PA and health-related topics in local newspapers in Missouri, USA, concluded that few health behaviour stories had a local angle, local quotes or call to action for individuals. Only one paper studying the impact of a lifestyle intervention programme on the readers of a regional newspaper has been found [5]. This study concluded that the intervention programme reached a large number of the newspaper's readers, and the press coverage resulted in 25000 weekly unique hits at the lifestyle intervention project's website. A limitation of the study was that it did not examine whether the readers were motivated to become more physically active. Nor did it measure the characteristics of those reading the lifestyle intervention features.

The main purpose of the present study was therefore to investigate how many of the newspaper's readers were motivated to become more physically active by reading the articles about a 13-week-long lifestyle intervention for four untrained adults. A secondary aim was to chart reader characteristics like gender, age and PA level.

\section{MATERIALS AND METHODS}

\section{Study design}

The study was a cooperative effort between the region's largest newspaper and the University of Stavanger, Norway. The newspaper published the stories of four untrained people who followed a 13-week endurance training programme in order to run a local $8.2 \mathrm{~km}$ park race. Two of four weekly training sessions were supervised running interval sessions which all readers were invited to join. The training progress for the four participants was covered in the newspaper, together with articles concerning PA, nutrition and lifestyle alteration. Readers' responses were mapped.

\section{Readers' responses}

During week 9 of the 13-week-long training intervention programme, a reader survey was sent to a representative sample (677 readers) of the newspapers readers. In addition to age and gender, these readers were invited to answer questions about their interest for these lifestyle articles. They were also asked if they were motivated to become more physically active after 
reading these articles and if reading the articles had any influence on their PA level (see Results). A total of 623 readers ( 371 men) between 20 and 82 years (mean $55.1 \pm 12.7$ years) responded to the survey. The number of hits on the project's web site was also registered throughout the project period.

\section{Newspaper's exercise participants}

Motivated readers, not engaged in regular endurance training, were asked to enrol in the 13-week intervention study. A total of 76 adults (70\% women) aged 21-65 years wanted to participate in the project. Two women aged 35 and 54 years, and two men aged 27 and 44 years, were interviewed and selected since they seemed to be representative of a large segment of readers. The participants provided written informed consent that all the data related to their training and testing could be published in the newspaper and used in a scientific publication. The study was approved by the Norwegian social science data services.

\section{Newspaper coverage of the project}

The daily circulation of the newspaper was 55000 , with an estimated readership of around 152000 (almost three readers per copy). At the end of the study, 31 articles had been published, distributed equally throughout the 13-week period, both in the newspaper and on the project's web site. The printed articles were mostly double sided and always contained one or more pictures. The project was covered on the newspaper's front page seven times. Twenty feature articles focused on the testing, training and progression of the four participants. Three articles focused on individuals (not the four main participants) who joined the weekly open training session. Nine articles focused on topics like exercise training principles, running technique, running shoes and nutrition. During the project period, 16 videos dealing with the above mentioned topics were published on the project's web site. Every Friday, the training programme for the coming week was published in the newspaper and on the newspaper's web site.

\section{Exercise training programme}

The four participants followed a 13-week training programme, which included four exercise sessions each week. The two supervised running interval sessions were at an intensity of $90 \%$ of maximal heart rate (HRmax) (16-21 min of effective running time). The other two other sessions were a variation of cycling, swimming and fast walking or running with low to moderate intensity. 


\section{Park race participation}

The four intervention participants ran the park race "Siddisløpet" ( $8.2 \mathrm{~km})$ after having completed the 13-week training period. To determine the number of participants in the race who were motivated to participate in the race because of publicity of the lifestyle intervention programme, we used the web-based enrolment programme. When registering for the race, participants were asked if they were motivated to participate because of the media coverage of the intervention programme. Since it was also possible to sign up by other means than the web-based enrolment programme, a total of 669 of 1203 enrolled participants (56\%) were asked this question.

\section{Physical fitness tests}

Maximal oxygen uptake $\left(\mathrm{VO}_{2 \max }\right)$ of the four participants was measured by treadmill running at the start and after 13 weeks of training using a Vmax 29 oxygen analyser (SensorMedics, Yorba Linda, CA, USA). The tests were performed using a standard test procedure [14]. The four participants also completed a $3050 \mathrm{~m}$ running test around a lake at baseline, and after 13 weeks of training.

\section{Statistical analysis}

Age of the readers was divided into five groups; under 40, 41-49, 50-59, 60-69 and above 69 years. To test differences between gender and motivational influence of the articles, a Chi-square test was used. To test differences between age groups, a Kruskal-Wallis test in combination with the chisquare test was used. PA level among readers who always or usually read the articles was compared with readers who never read these articles using a chisquare test. Variable values are presented as mean and standard deviation (SD). A p-value of less than 0.05 was regarded as statistically significant. All statistical analyses were performed using PASW Statistics 21 for Windows (IBM Corporation, Somers, NY, USA).

\section{RESULTS}

\section{Reader panel's response}

The distribution of readers' interest for the training intervention articles is shown in Figure 1. Twenty percent (127 of 623) reported that they always or usually read the articles, which was equal to the number who never read these articles. There was no significant difference in the distribution of men 
and women within these different categories. Forty percent of the readers under the age of 40 reported that they never read the articles, and only $9 \%$ reported that they always or usually read them. The distribution for this age group was different than the other age groups $(\mathrm{p}=0.004)$.

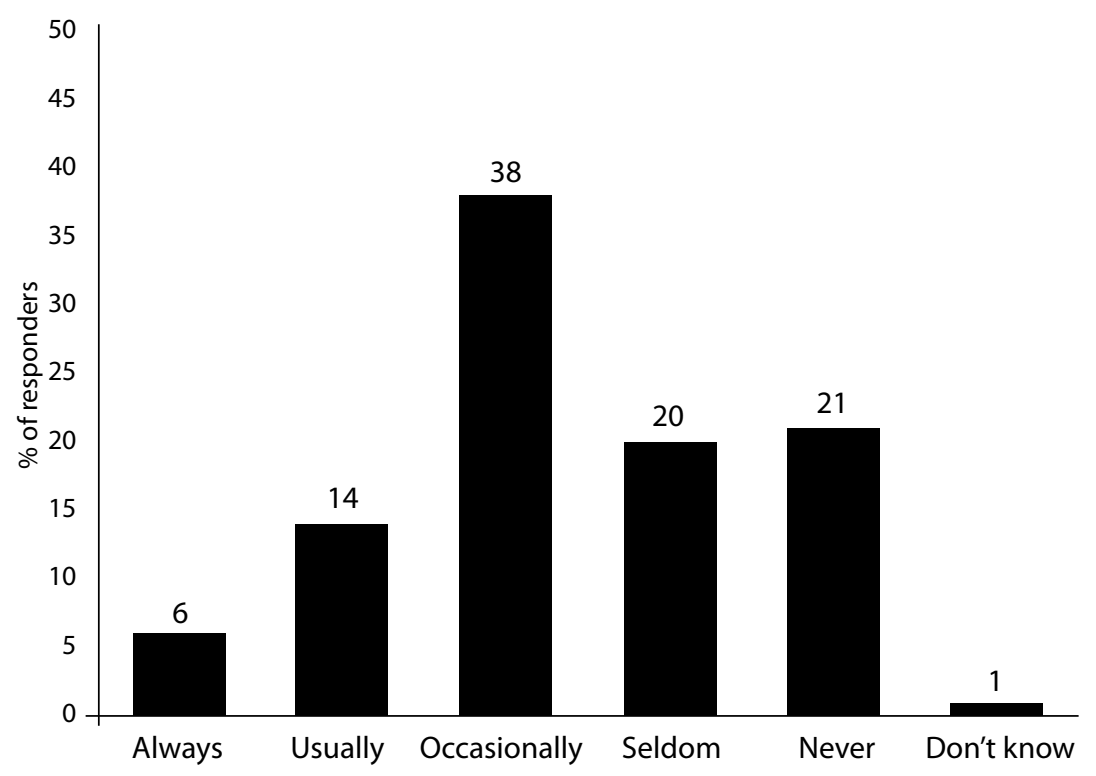

Figure 1. Percent distribution of readers $(n=623)$ answer to the question: Do you read the articles related to physical training, nutrition and health?

Of the 487 readers who always, usually, occasionally or seldom read the articles related the training intervention project, 102 readers ( $16 \%$ of all responders) answered "Yes" to the statement: "The articles about the training intervention project have motivated me to become more physically active". A total of 231 readers (48\%) answered "No" and 151 readers (31\%) answered "I don't know." There was no difference in gender distribution. Fourteen percent of those younger than 40 years answered "Yes", and corresponding data for those between $40-69$ years and 70 years and up was $24 \%$ and $12 \%$, respectively. Of the 102 readers answering "Yes", 83\% had been regularly physically active (30 min physical activity at least once a week) for at least six months. Twenty-eight percent of those performing 1-2 PA sessions per week answered "Yes." Corresponding data for those performing at least five PA sessions per week was 15\%.

Among those who seldom read these articles, only 3\% were motivated to become more physically active, while the corresponding number among those who always read the articles was $75 \%$. 
Among the 623 readers who answered the questions regarding their present PA level, $17 \%$ reported they were not regularly physically active, while $69 \%$ reported they have been regularly physically active for at least 30 min once a week for more than six months. Among those who never read the training intervention articles, $23 \%$ were not regularly physically active while $61 \%$ had been regularly physically active for more than six months. This was significantly different from those who always or usually read the articles, where only $6 \%$ were not regularly physically active and $91 \%$ had been regularly physically active for more than six months $(\mathrm{p}<0.001)$.

\section{Total response}

During the 13-week intervention period a total of 18037 (13 530) weekly unique users were registered at the training project's web site. The mean number of weekly web site views (number of total clicks into different project pages) was 29393 (23 595) (Figure 2).

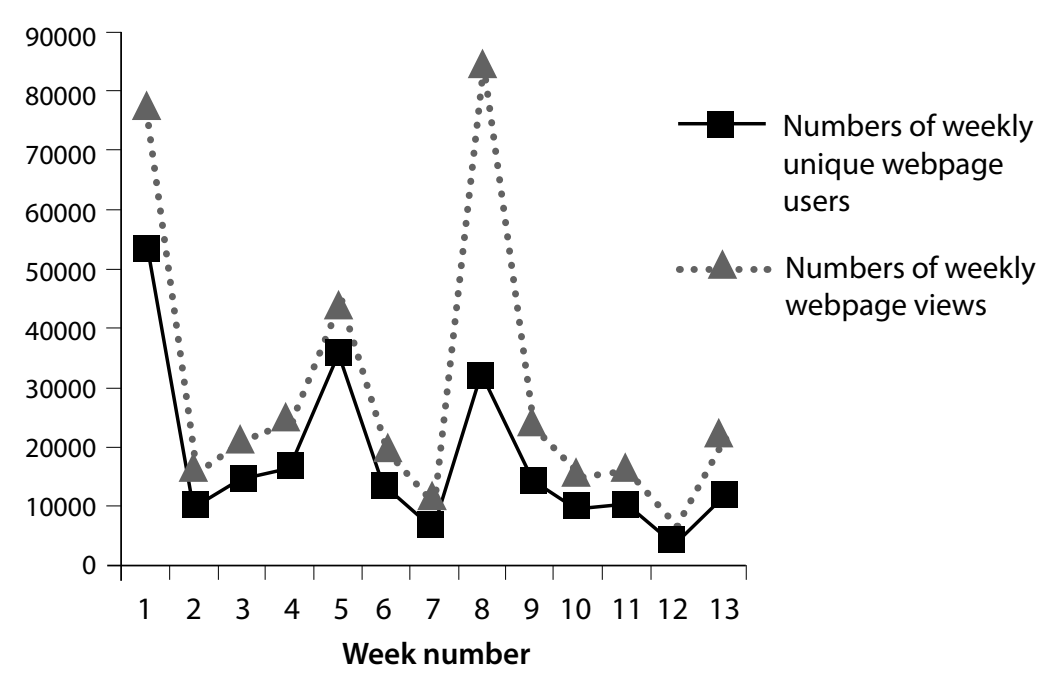

Figure 2. Weekly number of web site views and unique web site users during the lifestyle intervention period.

During the project period, the number of participants at the open interval training sessions varied between 80 and 180 participants (ages 10-82 years, $75 \%$ women). After the project period the participants at these open training sessions established a weekly running group, and six months after the project ended, around 60 people were still training together twice a week. 


\section{Training effects for the participants}

Throughout the 13 weeks of training, the four main participants achieved their goals during the lifestyle intervention period and experienced a significant increase in $\mathrm{VO}_{2 \max }$, a reduction in body mass index, and an improvement in the running test (Table 1).

Table 1. Maximal oxygen uptake $\left(\mathrm{VO}_{2 \max }\right)$, running time for 3050 -meter test and body mass index (BMI) at baseline and after 13 weeks of training.

\begin{tabular}{lccc|ccc|ccc}
\hline $\begin{array}{l}\text { Partici- } \\
\text { pants } \\
\text { (age) }\end{array}$ & \multicolumn{2}{c|}{ VO $_{2 \max }(\mathrm{ml} / \mathrm{kg} / \mathrm{min})$} & \multicolumn{3}{c|}{$\begin{array}{c}\text { Running time } \\
3050 \mathrm{~m}(\mathrm{~min} / \mathrm{sec})\end{array}$} \\
\cline { 2 - 11 } & $\begin{array}{c}\text { Base- } \\
\text { line }\end{array}$ & $\begin{array}{c}\text { After 13 } \\
\text { weeks }\end{array}$ & $\begin{array}{c}\text { Differ- } \\
\text { ence } \\
(\%)\end{array}$ & $\begin{array}{c}\text { Base- } \\
\text { line }\end{array}$ & $\begin{array}{c}\text { After 13 } \\
\text { weeks }\end{array}$ & $\begin{array}{c}\text { Differ- } \\
\text { ence } \\
(\%)\end{array}$ & $\begin{array}{c}\text { Base- } \\
\text { line }\end{array}$ & $\begin{array}{c}\text { After 13 } \\
\text { Week }\end{array}$ & $\begin{array}{c}\text { Differ- } \\
\text { ence } \\
(\%)\end{array}$ \\
\hline F1 (35) & 31.0 & 35.8 & 14.5 & $23: 12$ & & 29.07 & 26.30 & -6.1 \\
\hline F2 (54) & 30.7 & 37.5 & 23.1 & $22: 18$ & $17: 09$ & -23.1 & 20.20 & 19.62 & $-2,9$ \\
\hline M1 (44) & 41.5 & 46.6 & 12.3 & $19: 22$ & $14: 28$ & -25.7 & 28.8 & 27.17 & -5.8 \\
\hline M2 (27) & 37.1 & 40.5 & 9.2 & $20: 30$ & $15: 47$ & -23 & 27.76 & 27.00 & $-2,7$ \\
\hline
\end{tabular}

Note: $\mathrm{F} 1=$ female no $1 ; \mathrm{F} 2=$ female no $2 ; \mathrm{M} 1=$ male no $1, \mathrm{M} 2=$ =male no 2.

\section{DISCUSSION}

This study examined the motivational impact of an individually designed lifestyle intervention programme on the readers of a regional newspaper. The main findings were that $20 \%$ of the reader panel responded that they always or usually read the articles related to the training intervention project, and $16 \%$ answered that the articles motivated them to become more physically active. There were no gender differences between these groups, but readers below 40 years were less interested in these articles. Those not interested in these health-related articles were less physically active than those reading these articles.

It was found that $91 \%$ of the readers who usually or always read the articles reported that they had been regularly physically active for at least $30 \mathrm{~min}$ once a week for more than six months. Half of them reported they were physically active 3-4 times a week. Among those not reading these articles, four times more reported that they were not regularly physically active. It was also found that most readers who reported that they became motivated to be more physically active by reading the articles were already active 1-2 
times per week. Thus, the intervention described in present study has a large potential to increase $\mathrm{PA}$ in people who are already active. Assuming that the reader panel is representative for all of the 152000 readers, 24000 readers (16\%) have been motivated to become more physically active by reading the intervention articles. On the other hand, it seems clear that this intervention did not successfully motivate inactive readers, showing that those who could gain the most from participating in such an intervention are the most difficult to reach. There are probably several reasons why more sedentary readers were less interested in this intervention. First, the intervention participants were prescribed exercise four times a week for 13 weeks, and the main activity was running. It could be that inactive readers found this training programme too hard, and were not motivated enough to implement such a hard training programme. Second, a Norwegian study found that $76 \%$ of physically inactive subjects, i.e., those who did not engage in regular PA at least once every 14 days, wanted to engage in regular PA. The majority of this group reported that they required more initiatives or greater motivation to change their PA habits, and 35\% reported that they needed to be included in PA by friends or family. Many were also uncertain whether they would be able to start regular PA [12]. It could therefore be that highly sedentary adults need closer follow up and a stronger incentive than provided in this study.

Around 29000 clicks were registered from 18000 unique users every week on the project's web site. Figure 2 shows that there were large variations in the number of clicks from week to week, with peaks at week number 1, 5 and 8 . The project was covered on the newspaper's main web site on these week numbers, and was therefore more visible. This clearly illustrates that in order for the intervention to reach the greatest number of readers, primary coverage in both paper and web is of great importance.

One spin-off effect from the study was the large number of participants at the open training sessions. It was surprising that around $75 \%$ of these weekly participants were women since the readers of the articles were equally distributed between men and women. It could be that women in general are more motivated to exercise in a social setting than men. This is supported by a study by Forbes et al. [7] who found that among adults with type 2 diabetes, a greater proportion of women preferred to engage in activities with others. Since these open training sessions were led by experienced instructors, another explanation could be that more women than men prefer guided exercise sessions, which agrees with findings from previous studies $[7,16]$. At the end of this training intervention, the participants had established a social network and continued their weekly training sessions. They 
used Facebook to spread information about this training group and to share information and tips about running and other health issues.

The second spin-off effect was that $9 \%$ of the participants in the local park race reported that they were motivated to participate because of the publicity of the intervention project in the newspaper. This corresponds to the $10 \%$ increase in registrations from the previous year reported by the race organizers, and shows that some readers are motivated by setting a specific training goal. The importance of setting reachable goals in order to maintain participants' PA level over a longer period of time has been a focus in other studies $[1,3,13]$.

A total of 24000 readers were estimated to be more physically active by this lifestyle intervention. This indicates a great potential for promoting PA by publishing lifestyle interventions in a newspaper or other large scale media outlets. The highest impact of the intervention described in the present study among readers was for both men and women over 40 years old, who performed PA once or twice a week. A challenge for a similar study is to design an intervention that can motivate the most sedentary segment of the population to become more physically active.

\section{ACKNOWLEDGEMENTS}

This work was supported by the newspaper Stavanger Aftenblad and the University of Stavanger.

\section{REFERENCES}

1. Bushman BA. (2013) Reach your goals. ACSMs Health Fit J, 17(1): 4-7

2. Caburnay CA, Kreuter MW, Luke DA, Logan RA, Jacobsen HA, Reddy VC, Vempaty AR, Zayed HR. (2003) The news on health behavior: coverage of diet, activity, and tobacco in local newspapers. Health EducBehav, 30(6): 709-722

3. Cartwright MM. (2012) Realistic resolutions. IDEA Fit J, 9(10): 4-7

4. Chau J, Bonfiglioli C, Chey T, Bauman A. (2009) The Cinderella of public health news: physical activity coverage in Australian newspapers, 1986-2006. Aust N.Z. J Public Health, 33(2): 189-192

5. Dyrstad SM, Tjelta LI. (2013) Newspaper coverage effects on the promotion of a lifestyle intervention program. J Obes, 2013: 516767

6. Finnagan JR, Viswanath K. (1999) Massmedia and health promotion. Lessons learned, with implication for public health campaigns. In: Bracht N (ed). Health promotion at the community level. New advances. Newbury Park, CA: Sage; $119-126$ 
7. Forbes CC, Plotnikoff RC, Courneya KS, Boule NG. (2010) Physical activity preferences and type 2 diabetes: exploring demographic, cognitive, and behavioral differences. Diabetes Educ, 36(5):801-815

8. Hamamoto MH, Derauf DD, Yoshimura SR. (2009) Building the base: two active living projects that inspired community participation. Am J Prev Med, 37: 345-351

9. Hansen BH, Kolle E, Anderssen SA. (2014) Physical activity level among adults and the elderly in Norway. Updated analyzes based on new national recommendations in 2014. Report number IS-2183. Norwegian Directorate of Health, Oslo

10. Hillsdon M, Foster C, Thorogood M. (2005) Interventions for promoting physical activity. Cochrane Database Syst Rev, 25(1): CD003180

11. Kahn EB, Ramsey LT, Brownson RC, Heath GW, Howze EH, Powell KE, Stone EJ, Rajab MW, Corso P, Briss PA. (2002) The effectiveness of interventions to increase physical activity: A systematic review. Am J Prev Med, 22(4): 73-108

12. Ommundsen Y, Aadland AA. (2009) Physical inactive people in Norway. Who is inactive- and how can they be motivated for physical activity. Oslo, Norway: Norwegian Health Directorate, Norwegian Cancer Association, Norwegian Federation for Company Sport.

13. Teyhen DS, Aldag M, Centola D, Edinborough E, Ghannadian JD, Haught A, Jackson T, Kinn J, Kunkler KJ, Levine B, Martindale VE, Neal D, Snyder LB, Styn MA, Thorndike F, Trabosh V, Parramore DJ. (2014) Key enablers to facilitate healthy behavior change: workshop summary. J Orthop Sports Phys Ther, 44(5): 378-387

14. Tjelta LI, Tjelta AR, Dyrstad SM. (2012) Relationship between velocity at anaerobic threshold and factors affecting velocity at anaerobic threshold in elite distance runners. Int J Appl Sports Sci, 24(1): 8-17

15. Tucker JM, Welk GJ, Beyler NK. (2011) Physical activity in US adults compliance with the physical activity guidelines for Americans. Am J Prev Med, 40(4): 454-461

16. White JL, Ransdell LB. (2003) Worksite intervention model for facilitating changes in physical activity, fitness, and psychological parameters. Percept Mot Skills, 97(2): 461-466

\section{Correspondence to:}

Leif Inge Tjelta

Department of Education and Sports Science

University of Stavanger

N-4036 Stavanger, Norway

Phone: +475183 3523

Fax: +4751833450

E-mail: leif.i.tjelta@uis.no 